\title{
THE CONCEPTUAL OUTLINE OF PERCEPTION IN TERMS OF GREIMASSIAN SEMIOTIC THEORY
}

\author{
Anna Zaslonkina \\ Fedkovych Chernivtsi National University, Chernivtsi, Ukraine \\ annav.zaslonkina@gmail.com
}

\begin{abstract}
The current study addresses the nature of the relation between perceptual, cognitive, emotional processes, and linguistic experience within the observer framework. As an extension of the already conducted investigations into the semiotics of the sensible, the conceptual triad SENSE : FEELING : EMOTION is introduced. The study argues that the ternion in question is a component of human expressivity constituting the semiotic space of the thymic category. The synergism of cognitive-semantic characteristics of the three concepts under study corresponds to the basic level of categorisation in modern English. More significantly, the aim of the analysis is to consider the valency models of the names of the conceptual triad SENSE : FEELING : EMOTION as well as their collocability potential. The present paper highlights that the structures of predicate valency of conceptual dependencies FEELING $\rightarrow$ SENSE (the valency index equals 0,38 ) outnumber the analogous structures FEELING $\rightarrow$ EMOTION (the valency index equals 0,24). The structures of object valency of the combinations FEELING $\rightarrow$ EMOTION (the valency index is 0,9) prevail over the combinations SENSE $\rightarrow$ FEELING (with the valency index of 0,1). The data obtained confirm the idea that the correlation between observer and observable is twofold: cognitive-perceptual correlation denotes the observer's outward perspective, whereas cognitiveemotional correlation denotes the observer's inward perspective.
\end{abstract}

Keywords: category; concept; observable; observer; perception; lexical valency.

\section{Introduction}

The traditional issues of linguistics are now being reinterpreted with regard to the representation of linguistic knowledge by means of language as a semiotic system when cognitive-semantic description of language units and their discourse analysis are prioritised. The cognitive discursive paradigm of modern linguistics is supplemented by anthropocentric paradigm centred on the categories of observer and observable.

In consequence of interpretation of the observer as a language personality with perceptive, cognitive, and emotional capacities (Brdar, 2010; Power, Beattie, \& McGuire, 2017), the human organism as a holistic basis for construing divergent phenomena of perception keeps kindling the linguists' interest. Resultantly several linguistic schools have emerged. Corporeal semantics (Damasio, 1999; Fauconnier, 1998; Gärdenfors, 2000) and integrative theory of cognition (Poznanski, 2002) accentuate the immediate role of body and emotions in the cognitive processes, chiefly in constructing the worldview perceived by an individual. Biocognitive theory (Maturana, 1978; Varela, 1992) renders the subject of knowledge tantamount to the subject of perception. The linkage of cognitive structures (perception, language, thinking, and action) in the course of understanding the world by an individual is the focus of attention of Greimassian semiotics of the sensible (Greimas \& Fontanille, 2007; Schleifer, 2017). Greimas \& Fontanille were interested in studying language and discourse manifestation of the so-called thymic category (from the Greek word thymus meaning "related to passions and emotions within the entire physical structure of human organism" (p.13). The thymic category is therefore interpreted as the verbal form of cognitive activity of a linguistic persona who is classifying the conceptual structures denoting perceptual, emotional as well as cognitive facets of perception.

Taking into consideration the fact that people use basic-level concepts regularly (Bickerton, 1990; Rosch \& Lloyd, 1978), it is predicted that thymic category members can be selected, given that these category members are yielding information on the semantics of perception in the elementary concepts of modern English. We hypothesised that due to above-stated semiotic constraints the information on the thymic category can be conveyed by the conceptual triad SENSE: FEELING : EMOTION. Besides, cognitive and onomasiological features of the asserted basic-level concepts have not been analysed in linguistic studies. Thus, our goal is to extend previous research in the area by (a) gaining more clarity regarding the semiotic structure of the thymic category in modern English and (b) examining collocability patterns of the members of the thymic category.

\section{Method}

Initially, the structural method (namely the analysis of dictionary definitions and componential analysis) was employed to determine the inventory of the basic level concepts as members of the thymic category as well as to compile the thymic lexis corpus of modern English. Then, within the constructive method, the conceptual corpus-based analysis was applied following Lewandowska-Tomaszczyk and Wilson (2010) to 
outline the linguo-cognitive potential of the conceptual triad SENSE : FEELING : EMOTION. The research findings of Shuman, Clark-Polner, Meuleman, Sander, and Scherer (2015) and their theoretical underpinnings were used to describe the regularities of correlations among the structures of knowledge about perceptual, cognitive, and emotional facets of perception.

Evidence from existing research on cognitive linguistics (Piquer-Pz \& Alejo-Gonzz, 2016; Ruiz Moneva, 2010) confirms that the cognitive-logical model of reality is folded into signs and comprises both structural and semantic features of the context as well as their potential correlations. Strictly speaking, as Ufimceva (2004) indicated "by the nature of its nominative value a word establishes logical connections in syntagmatics manifesting the lexical valency" (p. 60). This assertion facilitates examination of conceptual triad SENSE : FEELING : EMOTION at a profound notional level. Hence, valency is considered to be the implicit index of a word to its combinations with other words, whereas collocability is viewed as a factual accomplishment of this capacity.

Komlev (2006) discerns the following collocability types of the two syntactically bound lexemes: "morphosyntactic, logical, semantic, and lexical" (p. 73). In fact, having examined the syntactic structures' meanings through the lens of their referential status, Nikitin (2009) noted that "sentence constituents (item and attribute) are projected onto arguments and predicates" (pp. 124-125). According to this perspective, arguments (alternatively termed as semantic-syntactic functions) correlate with adjuncts - optional semantic valencies of a predicate. The valency of basic and marginal thymic lexemes is gauged via prevailing semantic arguments, specifically agent (inanimate doer performing physical actions), experiencer (the subject experiencing all kinds of perception), perceptive (the object caused to experience all kinds of perception), means and channels of perception.

The research method to move beyond semantic features to the conceptual ones is propositional modelling of the conceptual triad SENSE: FEELING : EMOTION which presupposes assembling the predicate valencies of the concepts under study and clarifying their semantic arguments and adjuncts. The aim of propositional modelling, as Kosenko (2011) explains, is extracting the notional crux from the conceptual triad in question, the crux being reflected by "valency models anchored in the memory of native speakers in the form of underlying predications" (p. 97).

Lexical units selected from The British National Corpus Database (BNC), Questia Online Library, Online English Dictionary Wordnik, and 47 modern English fiction novels (a disk-based collection of modern English literature) constituted the data for the present study. Representative sampling was achieved on account of chronological homogeneity (the text fragments covering the period from the 1980s up to the present day). The combinations indicated below were selected using the continuous sampling method (the general wordage for predicates being 167782 and 53054 for arguments). Each valency channel was marked by an index.

Indices computation is a compelling form of the analysis of valency potential between the units of the conceptual triad SENSE : FEELING : EMOTION. Indices were interpreted by Levyckyj (2004) as "measures calculated by correlating disposal variables which are themselves subjected to modification of quantity" (p. 38). The valency index is assessed by means of the ratio Total R1 / Total R2, where R1 stands for the number of valencies of one position, R2 stands for the number of valencies of all positions. The analysis of lexical collocability is meant to reflect the major peculiarities of semantic connections between the names of conceptual units SENSE, FEELING, EMOTION, i.e. the essential assortment of valency efficiency of the units concerned.

\section{Results and Discussion}

Overall, the thymic sphere may not be subjected to direct observation, though the emotional states make the exception being viewed as "publicly observable" by Damasio (1999), while cognitive-perceptual states are designated by this scholar as "private, mental experience" (p. 38). Taking this assumption into account the subsequent viewpoint appears relevant: verbal fixating of symptomatic reactions and body conditions consistently associated with sensory perception becomes the basis for the evolvement of ideas about sense generating features of this particular sensory perception in the naïve worldview.

It may seem immediately obvious that the thymic category as a model of knowledge about diverse facets of perception correlates with the model of knowledge fixated in the modern English patterns, i.e. with the lexeme perceiving. Nonetheless, as Wierzbicka (1986) highlights, perceiving is too complex a notion to analyse words belonging to the category of perception and suggests this lexeme should be substituted for a small assortment of basic notions essential to the semantic system of the language. The idea of elementary senses with analogous semantics is represented in Wierzbicka's studies where she claims that the explanation of any phenomenon depends on the intuitive palpability of elementary concepts constituting its definition. 
Therefore, interpretation of complex meanings is not possible without "the initial set of elementary concepts not requiring clarification because they are inherent and intuitively recognizable" (Wierzbicka, 1999, p. 172). Accordingly, perceiving as a component of the lexical-semantic language system is externalised as a part of the lexical paradigm. This premise results in defining perceiving as the name of a notional continuum composed of the synonyms correlating with this word's semantics.

Within the individual's naïve worldview Apresjan (1995) solidly distinguishes the basic component FEELING (designated "semantic prime" (p. 356)). In the FEELING synonymic row selected from the online thesaurus and electronic database Wordnik (sense of, touch, sensation, (sneaking) suspicion, emotion, agitation, passion, love, sentiment, compassion, sensibilities, opinion, atmosphere, aptitude, consciousness) the attention is compelled to the partial inflectional paradigm of the noun SENSE (sense of, sensation, sensibilities) as well as the noun EMOTION which is the integral semantic feature of the synonyms for FEELING (agitation, passion, love, compassion).

The SENSE synonymic row (sensory faculty, feeling, appreciation, wisdom, purpose, meaning, reason, understanding, sensation, sensibility, apprehension, recognition, discernment, judgment, notion, opinion, import, signification, perception, intelligence, consciousness, essence, direction, common sense) partially agrees with the one of FEELING, specifically both rows share the lexemes sensation, sensibility(-ies), opinion, consciousness. The EMOTION synonymic row (feeling, passion, instinct, excitement, trepidation, perturbation, agitation, tremor, affect) similarly shares two lexemes with the FEELING row, namely passion, agitation. Besides, the lexeme feeling occurs in the synonymic rows of SENSE and EMOTION.

Labelling FEELING "conceptual and lexical universal", i.e. a paramount tool when comparing two cultures, Wierzbicka (1996) classifies EMOTION as a "conceptual means of studying solely English language and culture on account of its complexity and restricted cultural conditionality" (p. 389). Furthermore, the corporeal semantics disciple Damasio (1999) brings to notice the fact that feeling and emotion consistently need to be complemented: "But we only know that we feel an emotion when we sense that emotion is sensed as happening in our organism" (p. 279). Thus, the scholar indicates SENSE as a potential basic element of modern English semantics next to FEELING and EMOTION. The selected triad of the basic semantic elements belonging to the same part of speech is distinguished by the threefold marginality because the lexemes sense, feeling, emotion take up a borderline position among the human systems identified by Apresjan (1995, p. 357-373).

Consequently, the thymic category correlates with the notion of a person as a semiotic phenomenon, the person's image-schema being reconstructed via language data. The semiotic space of the thymic category in modern English is characterised by the linguo-cognitive universal FEELING and by the British culturespecific concepts SENSE, EMOTION alike. The triad itself is a result of the basic level categorisation processes, the triad's verbalisation mediating the description of the structures of knowledge of what was perceived by means of language phenomena.

As predicted, the semiotic space of the thymic category in modern English is constituted by the conceptual triad SENSE : FEELING : EMOTION taking into consideration the fact that the verbal forms sense, feeling, emotion as well as their paradigmatic groupings are connected with the knowledge structures related to perceptual, cognitive, emotional facets of perception. These results are in line with the findings of Bell, Forster, and Drake (2015) as well as Hanczakowski, Beaman, and Jones (2017) due to the case that the alleged knowledge structures are generalised and classified by the thymic category. The latter eventuates in encompassing the concentration of the most distinctive analogous features among the units of the conceptual triad SENSE : FEELING : EMOTION. Content word representatives of each unit of the triad under study constitute the thymic lexis corpus of modern English. When investigating the language expression of the thymic category members, the thymic category itself is regarded as a linguistic construct of the basic categorial level, whereas the thymic nouns sense, feeling, emotion are deemed basic and the thymic lexemes belonging to different parts of speech as well as collocations and idioms are deemed marginal or peripheral.

\section{The valency status of the thymic verbs}

Thymic verbs fulfil the function of predicates and represent ontological characteristics of thymic conditions and actions showing agreement with experiencer, i.e. the subject corresponding to the bearer of the thymic condition. Experiencer can be represented by the singular personal pronoun conveying either perceptual or cognitive or emotional state as a result of an individual experience, for example Luckily I was feeling in a good mood (OALD, p. 429), as well as by the plural personal pronoun conveying the unified thymic experience, for example, We all felt the force of her arguments (OALD, p. 429).

The subject of the thymic, ordinarily sensory perceptual action (agent) is manifested by nouns denoting technical units (equipment that senses the presence of toxic gases (OALD, p. 1072) or substances (the water 
feels warm (OALD, p. 429). Besides, in modern English the shift of experiencer to the position of agent is observed (Her head felt as if it would burst (OALD, p. 429), along with the semantic deficit of the subject of the thymic condition or action (It felt strange to be back in my old school (OALD, p. 429).

The object of the thymic action known as perceptive is represented by nouns and pronouns accompanying basic and marginal thymic verbs. Perceptive signifies the essential feature of the situation which preceded the feasible thymic action and will conceivably gain new thymic quality under the stimulus of this action: How can we emotionalize the entire consumption experience? (BNC, n.d.). Perceptive can be represented by an animate being (patient), its sensorimotor characteristics being perceived by the subject, for instance, He sensed Dennie approach the pool (Brin, 1984, p. 80). In addition, perceptive can be missing before the moment of the thymic action or it can occur as the manifestation of the latter, for instance, But I sense an attempt at an end run (Brooks, 1995, p. 79).

In case the thymic action is directed at an abstract or concrete object and is of an informative nature, the whole clause may be imperative: "I would feel foolish just speaking some of this stuff, and - ... " "Then feel it!?" (Piers, 1991, p. 39) (the object is abstract); Feel its weight from here, child (Brooks, 1997, p. 163) (the object is concrete).

Pseudoperceptive is a kind of a false object represented by the pronoun it. Pseudoperceptives precede modifiers, that is to say, diverse qualities of a situation, for example, The UK felt it necessary and very important to be a member of LOFT (BNC, n.d.).

On the whole, modifiers tend to be placed in postposition to the thymic verb-predicate to feel: Dirk began to feel very, very tired at the way the day was working out (Adams, 1991, p. 63) (the attribute is functioning as an argument, not adjunct); He felt as if he had just seen zero and infinity converge (Piers \& Farmer, 1992, p. 40) (the subject's inner quality is displayed by means of an additional predicate structure as a part of the sentence).

The compulsory arguments can be illustrated by the adverbial modifier of place fulfilling the following functions: valency of the thymic predicate (... the poet Wordsworth, who claims to have felt in nature: a presence that disturbs me with the joy or elevated thoughts (BNC, n.d.)); addressee functioning as an active or passive participant of the thymic activity signified by the predicate (but I felt sorry for him (BNC, n.d.)); reciprocant serving as an analogue of the participant of the symmetric thymic ratio (He was not supporting me in the way I felt he should support me (BNC, n.d.)).

The mediator of semantic-syntactic subordinacy between predicative units, one of which belongs with the thymic lexis corpus, appears to be an optional argument (cf. ... country boys sensing that nationalism rather than colonialism was a path of honour (BNC, n.d.) and We feel $\underline{\emptyset}$ we have been duped (BNC, n.d.)).

The denotative relationship between a feeling, a sense, and their bearer is typically described through the medium of a thymic verb + noun with the meaning of a feeling or sense: Maia sensed anger in the tense silence of the Persim cloneling (Brin, 1994, p. 86). The noun can be preceded by attributive adjectives: I feel a strange, guilty happiness (Banks, 2002, p. 2), whereby the noun itself can belong with the thymic lexis corpus: I feel a bizarre sense of loss and yearning (Banks, 2002, p. 25); The other said nothing, but Stoner sensed a turmoil of emotions (Bova, 1991, p. 65). However, the degree of emotional connotation of the verbs to emote, to emove, to emotionalise minimises the need to add nouns expressing feelings: On one other note, Suzanne, when we get into debates like abortion, we emotionalize the issue (Wordnik, n.d.).

The past participle of the basic thymic verbs can appear as the predicate of several arguments concurrently: What are the felt needs, aspirations, hopes, fears? (BNC, n.d.). According to their informational significance the number of essential as well as subsidiary valancies of the thymic predicates varies within the conventional confines 1 - 3: to emotionalise, to feel, to sense etc. (what? how? where?), e.g. He does "emote" (1. What?) a feeling about direction, he simply sounds like a dour economist, take a look if you don't believe me (Wordnik, n.d.); Carl sensed (1. What?) tension crackle (2. Where?) across the conference table (Bova, 1989, p. 9); I was pleased we were talking about girls because I felt (1. How?) clearly (2. What?) this was a subject (3. Where?) where Andy's two extra years didn't really count (Banks, 2002, p. 21).

A related point to consider is a thymic verb functioning as a predicate thus determining the status and the number of arguments and, what is noteworthy, manifesting the valency information on itself. Thus, the thymic verb approaches the alleged "pragmatic connectors" (the term first introduced by Fauconnier (1998, p. 11-12) as it verbally mediates the connections between the person's inner space and the person's perceptual field. 
The valency status of the thymic nouns, adjectives, and adverbs

The basic and marginal thymic nouns signify the forms of perceptual, emotional, and cognitive experience (sense, sensation, sensibility, sensitiveness, emotion, emotionality, feel, feeling, etc.), range of tools equivalent to these lexical patterns (feeler, sensor, sensitometer, etc.), along with the lexemes designating cognitiveemotional competences and their carriers (emotionalism, sensationism - sensationist, sensualism - sensualist, sensism - sensist, etc.). For the thymic noun structure the following profiles of the subject in the preposition are common: the one with a personal pronoun (He knew he should be afraid, but his emotion seemed to have shorted out that stage, leaving him strangely clearheaded (Anthony \& Margroff, 1991, p. 9) or Still, my feeling for Colene is such that I prefer not to be guilty of what disturbs her, even if it is too late for such restraint (Piers, 1991, p. 68)); the one with the name of an animate being, particularly a proper name in the possessive case (Mr. Hodges' misplaced emotionalism is his own problem (Wordnik, n.d.)).

Object relations between units of the thymic lexis corpus are expressed by means of prepositions at, of, for, in, to next to the controlled noun (emotions at the verdict (OALD, p. 379), a sense of purpose (OALD, p. 1071), a feeling for colour (OALD, p. 429), sensitivity to light (OALD, p. 1072) or by the subordinate clause with relative pronouns-specifiers that, which (This strong sensationism, which has similarities with Locke's position, was coupled as has already been noted, with an enlightenment stance (Wordnik, n.d.)).

Results from the current study suggest that diversification of means of rendering emotivity via thymic nouns and verbs accompanying the names of emotions might be attributed to the temporal remoteness of the perception phases. The boundary between feelings, senses, and psychological features is mobile and sporadic: he felt fear - the emotion of fear is perceived as the one experienced at the moment of triggering; he had the feeling of fear - the similar phenomenon is conceptualised as the one of mental nature.

The features of basic and marginal thymic nouns are assigned by the modifiers co-occurring with them (heated emotionality (BNC, n.d.), musical sensibility (OALD, p. 1072). Furthermore, the structures with the thymic nouns-adjuncts can follow the prepositions (with emotion (OALD, p. 379), by the feel (OALD, p. 429).

Basic and marginal thymic adjectives and adverbs refer to both: subject which constitutes the nucleus of the proposition (The incident was sensationally reported in the press (OALD, p. 1071) and object of the thymic impact (I'm drawn to the poetic, sensuous qualities of her paintings (OALD, p. 1072).

The predicative syntactical function of the thymic adjectives is determined by their meaning of state synchronously with the fixed evaluative senses, e.g. emotionless society (BNC, n.d.) or sensory perceptual qualities, e.g. sensory organs (OALD, p. 1072).

Thymic adjectives can combine with qualitative adjectives thus acquiring the status of intensifiers, for instance: a trend within the counterculture which sees itself as, so to speak, "sensuously spiritual" (BNC, n.d.) and with the past participle of the verbs circumstantiating pragmatic and notional significance of the latter, e.g. I try not to become emotionally involved (OALD, p. 379). Thymic adjectives can co-occur with non-thymic adjectives-intensifiers, e.g. Health care is a politically sensitive issue (OALD, p. 1072).

\section{Thymic verb-centred valency channels}

The above described cases of collocability of the names of the conceptual triad SENSE : FEELING : EMOTION are recorded in lexicographic sources. They are withal exhibits of the typical valency, the phenomenon differentiating the valent lexical meanings as determined by generality level, the latter depending on arguments with which a lexical unit semantically correlates. Still, the organisation of the mental lexicon within the cognitive space of consciousness cannot be of a strictly expressed dictionary character. From this perspective, the typical valency may be regarded as an invariant of valency channels or concrete means of recording how collocability course instances are put into effect. The paradigmatic way in which the valency channels between different verbal representatives of the conceptual triad SENSE : FEELING : EMOTION are objectified is of especial importance. Originally, the valency channels containing a thymic verb were analysed, the study of the channels devoid of the thymic verbs, but featuring thymic nouns followed.

VALENCY CHANNEL FEELING $\rightarrow \mathrm{SENSE}_{0,3}$ : to feel a sense + noun (this combination was recorded 56704 times), e.g. (a) Asked whether she ever feels a sense of danger ... (BNC, n.d.). (b) ... and feels a sense of outrage (BNC, n.d.). The combination of the verb to feel with the argument performing the syntactical function of objective complement (the noun-perceptive sense linked to the nouns danger and outrage) is observed. The noun can denote outer conditions constituting the basis for the occurrence of the thymic situation (illustration $a$ ) and its inner causes (illustration $b$ ).

VALENCY CHANNEL SENSE $\rightarrow$ FEELING $_{0,2}$ : to sense a feeling $+($ adj. $)+$ noun (this combination was recorded 34816 times), e.g. It lasted about a minute before fading and they both sensed a feeling of 
impending danger (BNC, n.d.). The combination of the verb to sense with the noun-perceptive feeling which is the subjected constituent of the channel accompanied by the adjective impending with the noun danger (both functioning as specifiers of the perceptive) was detected.

VALENCY CHANNEL FEELING $\rightarrow$ EMOTION $_{0,08}:$ to feel (an) emotion + (circumstance) (this combination was registered 13517 times), e.g. It is nevertheless a modified version of that same emotion felt in an actual event (BNC, n.d.). The verb to feel followed by the noun-perceptive emotion which is the subjected constituent of the channel is observed. FEELING as predicative centre of the sentence can be semantically equal to SENSE: the sentence Her words filled me with a blaze of emotion that I felt physically in my chest, radiating through my body (BNC, n.d.) is conceptually equivalent to the sentence Her words filled me with a blaze of emotion that I sensed in my chest, radiating through my body.

VALENCY CHANNEL FEELING $\rightarrow$ SENSE $_{0,03}$ : to feel + (adj.) + sensation (this combination was registered 6493 times), e.g. The woman felt a soothing sensation, then a warm glow (Questia, n.d.). The noun-perceptive sensation corresponding to the argument follows the verb to feel and can be congruent with adjectives.

VALENCY CHANNEL FEELING $\rightarrow \mathrm{SENSE}_{0,05}$ : to feel sensational / sensitive / sensible (about) (this combination was recorded 8677, 9867, 8752 times respectfully), e.g. Eastman feels especially sensitive about his name (Questia, n.d.). The combination of the verb to feel with the adjective-attribute sensitive as an absolute argument, i.e. the essential valency feature of the predicate feels was discovered. Preposition about is directing the course of the channel's collocability with the succeeding argument.

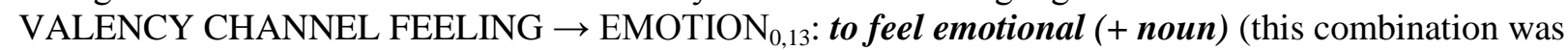
recorded 22306 times), e.g. When I saw them I immediately felt an emotional connection (Questia, n.d.). The combination of the verb to feel with the adjective emotional (the latter fulfilling the function of a modifier of the noun-perceptive connection) was revealed. The adjective emotional can function in the sentence without being accompanied by the perceptive, e.g. Emma Bunton on her new musical theatre album made her feel emotional (Questia, n.d.).

VALENCY CHANNEL FEELING $\rightarrow$ EMOTION $_{0,03}$ : to feel emotionally + adj. (this combination was registered 6650 times), e.g. The basic business of looking after them felt so emotionally wearing that there seemed little rime left (BNC, n.d.). The verb to feel collocates with the adverb emotionally which is the adjunct of the predicate-argument structure. The adjunct emotionally represents the adverbial modifier of the thymic situation and despite its optionality intensifies the adjective wearing in this manner denoting the reinforced conditions of the thymic action.

Considering the testimony of the predicative valency exponents, the concept FEELING proves to be both semantically and lexically most interpretive. Hence, it may be regarded the central member of the thymic category. The semantic-syntactic capacity of the combinations to feel a sense (of danger) having the index 0,3 and to sense a feeling (of danger) with the index 0,2 indicate the dual nature of what is observed (observable), scilicet its outward and inward perspective. The outward perspective is determined by the presence of the objects of perception, particularly the external stimuli and is verbalised by the predicate to sense. The inward perspective is regulated by the image built up in the observer's consciousness and is verbalised by the predicate to feel. The observable exists in the naïve worldview provided the outward and inward perspectives integrate.

Sørensen, Thellefsen, and Thellefsen (2016) have provided possible explanation for the present results. Specifically, they noted that emotion is a flavour of cognition. The current research provides evidence for supporting their findings. The predicate to feel prevails against the others and sets the valency course thus displaying the observer primarily as a personality genuine in existence, the one acquiring intuitive thinking behind intrinsic opinions and only then as a versatile subject of perception. The total index of the valency channels FEELING $\rightarrow$ SENSE reaches 0,38 and FEELING $\rightarrow$ EMOTION sets up 0,24. Therefore, the proposition of the utterance with thymic connotations is coordinated under the principle of cognitive perceptual correlation between observer and observable. The quantitative superiority of conceptual reliances FEELING $\rightarrow$ SENSE over those of FEELING $\rightarrow$ EMOTION asserts the possibility of replacing the whole thymic category by its segment, whilst the essential perceptual, cognitive, and emotional facets of perception are preserved.

\section{Thymic noun-centred valency channels}

VALENCY CHANNEL SENSE $\rightarrow \mathrm{FEELING}_{0,1}$ : sensitivity + to + feelings (this combination was recorded 5582 times), e.g. Clearly there's no sensitivity to feelings at all (Questia, n.d.). The compulsory valency feature of the predicate is (to be) is observed, the one expressed by the noun sensitivity. The latter is fairly complemented by a valid argument - the noun feelings. 
VALENCY CHANNEL FEELING $\leftrightarrow$ EMOTION $_{0,5}$ : feelings and emotions (this combination was recorded 24791 times), e.g. Or that the girl is unusually stable in her feelings and emotions and is in love with the man concerned? (BNC, n.d.). The synonymous and stylistic affinity of the nouns-arguments feeling and emotion is revealed because they are yielding a modifier with the adverbial-adjectival group unusually stable being the integral characteristic of the latter. This condition allows the syncretism of both, modifier and complement.

VALENCY CHANNEL SENSE $\leftrightarrow$ EMOTION $_{0,06}$ : sensations and emotions (this combination was registered 3424 times), e.g. For me it is more about the soul, sensations, emotions rather than the shape of a body (Wordnik, n.d.). The correlates of the predicate to be verbalised by the synonymously and stylistically converged nouns-arguments sensations and emotions have been detected.

VALENCY CHANNEL FEELING $\rightarrow$ EMOTION $_{0,4}$ : emotional feelings (this combination was registered 19257 times), e.g. But at a deeper, kind of gut level, the emotional feelings we find there ... (BNC, n.d.). The adjective emotional preceding the noun feelings is discovered, whereas both of the argumentscomplements denote the processual abstract object at which the thymic action is directed.

As it has been illustrated above, the positions indispensable for the predicate are represented by the arguments, i.e. collocations of the thymic nouns or a thymic noun and a thymic adjective / adverb. The total index of the combinations FEELING $\rightarrow$ EMOTION reaches 0,9 exceeding that of SENSE $\rightarrow$ FEELING $(0,1)$. Making allowance for the fact that in two of the valency channels the concepts FEELING and SENSE are equivalent to the concept EMOTION, the thymic arguments may be classified as the exponents of emotional state. Supplementary to it, the concept SENSE is objectified within valency channels and verbalised by the speech formulae: to feel a sense + noun, to feel + (adj.) + sensation, to feel sensational / sensitive / sensible (about), sensitivity + to + feelings, sensations and emotions. This concept is considerably more frequently observer-oriented, the observer operating as the subject of evaluation.

\section{Conclusions}

Within the predicate-argument structure, the observable presents itself solely provided that the outward and inward perspectives of the observer integrate. By virtue of this circumstance, the cognitive perceptual correlation between observer and observable becomes the prerequisite for the inclusion of the predicate into a sentence, howbeit the inclusion of the argument is stipulated by cognitive assessing and cognitiveemotional correlation of observer and observable. The thymic category reveals the tendency towards isomorphism of its members, while its essential perceptual, cognitive, and emotional facets can be substituted for the names of the concept FEELING in predicate valencies or for the names of the concept SENSE in object valencies. Further research into conceptual universals bearing the information on feelings, senses and emotions as those inherent in the corporal framework and correspond to the basic level of categorisation appears fully justified, because it can help obtain a definitive answer to the question about the role of the thymic lexemes in the formation of language worldview. Other than that, a comprehensive description of the thymic category taking into account its peculiarities of functioning in different discourse types can be performed.

\section{References:}

Adams, D. (1991). The Long Dark Tea-Time of the Soul. New York: Pocket Books.

Adams, D., Adams, R., Ahern, J., Aldiss, B., Alexander, L., Allston, A., ... Zelazny, R. (2003). Biblioteka sovremennoj anglojazychnoj literatury (serija Master Media) [The library of modern English literature (Master Media series)]. [CD ROM]. St. Petersburg, Russia: BHV-Peterburg.

Apresjan, Y.D. (1995). Izbrannye trudy. V 2 tomah. Tom II: Integralnoe opisanie jazyka i sistemnaja leksikografija [Selected Works. In 2 Volumes. Vol. II: The integrated description of language and system lexicography]. Moscow, Russia: Jazyki slovjanskoj kultury.

Banks, I. (2002). Complicity. New York: Simon \& Schuster.

Bell, D., Forster, K., \& Drake Sh. (2015). Early semantic activation in a semantic categorization task with masked primes: Cascaded or not? Journal of Memory and Language, 85, 1-14. https://doi.org/10.1016/j.jml.2015.06.007

Bickerton, D. (1990). Language and species. Chicago: University of Chicago Press.

Bova, B. (1989). Cyberbooks. New York: Tor Books.

Bova, B. (1991). Star Brother. New York: Tor Books

Brdar, M. (2010). Review of the book New Directions in Cognitive Linguistics by V. Evans \& S. Pourcel (Eds.). Review of Cognitive Linguistics, 8, 363 -375. https://doi.org/10.1075/rcl.8.2.06brd

Brin, D. (1984). Startide Rising. New York: Spectra.

Brin, D. (1994). Glory Season. New York: Spectra.

Brooks, T. (1995). The Tangle Box. New York: Del Ray.

Brooks, T. (1997). First King of Shannara. New York: Del Rey.

Damasio, A. (1999). The Feeling of What Happens: Body and Emotion in the Making of Consciousness. New York: Harcourt Brace.

Fauconnier, G. (1998). Mental Spaces: Aspects of Meaning Construction in Natural Language. Cambridge: Cambridge University Press.

Free Online Thesaurus (n.d.). Retrieved June 15, 2017, from: http://www.thesaurus.com/ 
Gärdenfors, P. (2000). Conceptual Spaces: The Geometry of Thought. Cambridge, Massachusetts: MIT Press.

Greimas, A.J., \& Fontanille, J. (2007). Semiotika strastej. Ot sostojanija veshchej k sostojaniju dushy [Semiotics of the sensible. From the state of matter to the state of mind] (I.G. Merkulova, Transl.). Moscow, Russia: URSS.

Hanczakowski, M., Beaman, C. Philip, \& Jones, Dylan M. (2017). When distraction benefits memory through semantic similarity. Journal of Memory and Language, 94, 61-74. https://doi.org/10.1016/j.jml.2016.11.005

Komlev, N.G. (2006). Komponenty soderzhatelnoj struktury slova [Components of the content structure of the word]. Moscow, Russia: KomKnyha.

Kosenko, Y.V. (2011). Osnovy teorii movnoi komunikacii [Fundamentals of linguistic communication theory]. Sumy, Ukraine: Sumy State University.

Levyckyj, V.V. (2004). Kvantitativnye metody v lingvistike. [Qantitative methods in linguistics]. Chernovtsy, Ukraine: Ruta

Lewandowska-Tomaszczyk, B., \& Wilson, P. (2010). A contrastive perspective on emotions: surprise. Review of Cognitive Linguistics, 8, 321-350. https://doi.org/10.1075/rcl.8.2.04lew

Maturana, Humberto R. (1978). Biology of Language: The Epistemology of Reality. In G. Miller, E. Lenneberg (Eds.), Psychology and Biology of Language and Thought. New York: Academic Press. Retrieved 15 February, 2015, from Slide Share website, https://www.slideshare.net/Longsthride/78-biology-of-language-humberto-1978

Nikitin, M.V. (2009). Osnovy lingvisticheskoj teorii znachenija [Fundamentals of linguistic theory of meaning]. Moscow, Russia: Knizhnyj dom "LIBROKOM".

Online English dictionary Wordnik (n.d.). Retrieved June 15, 2017, from http://www.wordnik.com

Oxford Advanced Learner's Dictionary of Current English (2001). Oxford: Oxford University Press.

Piers, A. \& Farmer, Ph. J. (1992). The Caterpillar's Question. New York: Ace Books.

Piers, A. \& Margroff R. (1991). Dragon's Gold. New York: Tor Books.

Piers, A. (1991). Virtual Mode. New York: Ace Books.

Piquer-Pz, \& Alejo-Gonzz, R. (2016). Applying Cognitive Linguistics: Identifying some current research foci (figurative language in use, constructions and typology). Review of Cognitive Linguistics, 1, 1-20. https://doi.org/10.1075/rcl.14.1.01piq

Power, N., Beattie, G., \& McGuire, L. (2017). Mapping our underlying cognitions and emotions about good environmental behavior: Why we fail to act despite the best of intentions. Semiotica, 215, 193-234. https://doi.org/10.1515/sem-2016-0035

Poznanski, R. (2002). Towards an integrative theory of cognition. Journal of Integrative Neuroscience, 01, 145-156. https://doi.org/10.1142/S0219635202000086

Questia Online Library (n.d.). Retrieved June 15, 2017, from http://www.questia.com/

Rosch, E., \& Lloyd, B.B. (1978). Cognition and Categorization. Hillslade, NJ: Lawrence Erlbaum.

Ruiz Moneva, A. (2010). Relevance-theoretical versus pragmatic and cognitive approaches to coherence: A survey. Review of Cognitive Linguistics, 8, 19-65. https://doi.org/10.1075/rcl.8.1.02rui

Schleifer, R. (2017). The semiotics of sensation: A. J. Greimas and the experience of meaning. Semiotica, 214, $173-192$. https://doi.org/10.1515/sem-2016-0182

Shuman, V., Clark-Polner, E., Meuleman, B., Sander, D., \& Scherer, Klaus R. (2015). Emotion perception from a componential perspective. Cognition and Emotion, 31, 47-56. http://dx.doi.org/10.1080/02699931.2015.1075964

Sørensen, B.,Thellefsen, T., \& Thellefsen M. (2016). The meaning creation process, information, emotion, knowledge, two objects, and significance-effects: Some Peircean remarks. Semiotica, 208, 211-34. https://doi.org/10.1515/sem-2015-0117

The British National Corpus Database (n.d.) Retrieved July 18, 2017, from http://www.natcorp.ox.ac.uk

Ufimceva, A.A. (2004). Tipy slovesnyh znakov [Types of verbal signs]. Moscow, Russia: Editorial URSS.

Varela, F.J. (1992). Autopoiesis and a Biology of Intentionality. In B. McMullin, N. Murphy (Eds.), Autopoiesis and Perception: A Workshop with ESPRIT BRA 3352 (pp. 4-14). Dublin, Ireland: Dublin City University. Retrieved September 23, 2016, from CEPA.INFO website, http://www.univie.ac.at/constructivism/archive/fulltexts/1274.html

Wierzbicka, A. (1986). Vosprijatie: semantika abstraktnogo slovarja. [Perception: semantics of abstract vocabulary]. Novoe $v$ zarubezhnoj lingvistike. Logicheskij analiz estestvennogo jazyka, XVIII, 336-369. Moscow, Russia: Progress.

Wierzbicka, A. (1996). Jazyk. Kultura. Poznanie [Language. Culture. Cognition]. Moscow, Russia: Russkie slovari. Retrieved December 12, 2016, from https://komyshkovaad.files.wordpress.com/2014/10/yazyk_kultura_poznanie.pdf

Wierzbicka, A. (1999). Semanticheskie universalii $i$ opisanie jazykov. [Semantic universals and description of languages]. (A. Shmelev, Transl.). Moscow, Russia: Jazyki russkoj kultury. 